\title{
The Feasibility and Acceptability of the
}

\section{Assessment of Physiotherapy Practice Instrument During Pre-Registration Student Placements}

\author{
Lauchlan D., Gray H., Moffat F., Shanmugam S. \\ School of Health and Life Sciences, Glasgow Caledonian University.
} Contact: Douglas Lauchlan, School of Health and Life Sciences, Glasgow Caledonian University, G4 OBA. douglas.lauchlan@gcu.ac.uk 0044 (0)141 3318862

Relevance

- All physiotherapy pre-registration programmes require that a significant proportion of the curriculum is conducted in clinical practice placements.

- A persistent difficulty in assessing students whilst on placement centres around the transparency and consistency of assessment, particularly when there are many practice educators involved over a wide range of geographically diverse placement settings.

- The Assessment of Physiotherapy Practice (APP) Instrument is a 20-item instrument covering seven domains; supported by performance indicators for each item to guide educators.

- It is a valid ${ }^{1}$ and internally consistent ${ }^{2}$ instrument for the assessment of entry-level competence in physiotherapy with high levels of inter-rater reliability and test-retest reliability.

Approach/Evaluation

- A series of consultation meetings were held over a calendar year with all relevant stakeholders, including professional body representatives, external examiners, practice educators, students, other university representatives and internal academic quality office personnel.

- Feedback from these consultations assisted in the design of future training workshops for practice educators in the use of the APP instrument.

The APP instrument was piloted concurrently with the University's previous assessment form and feedback was sought from pilot sites.

Qualitative data were collected from undergraduate and postgraduate pre-registration students and practice educators using structured feedback focus group sessions and interviews.

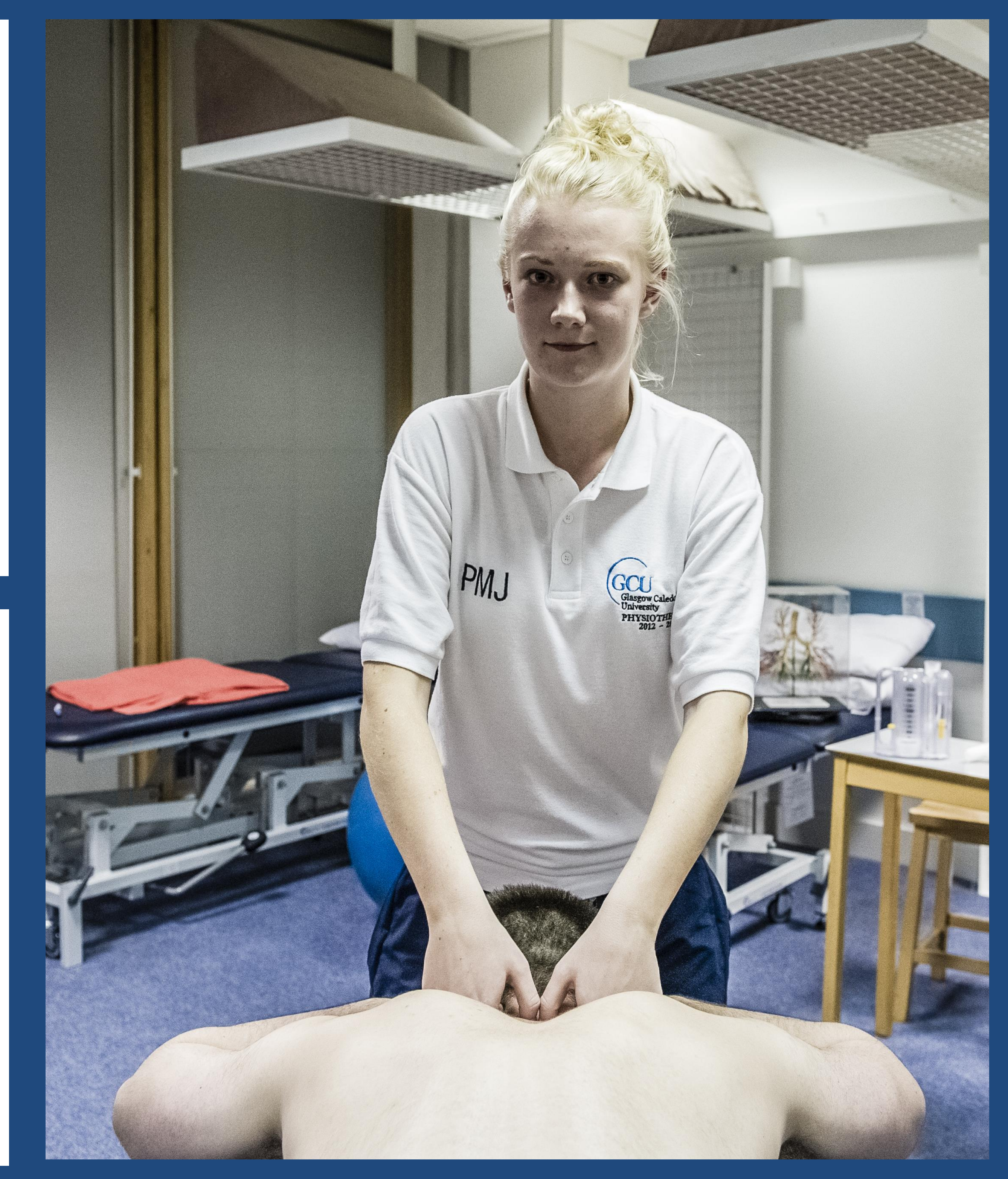

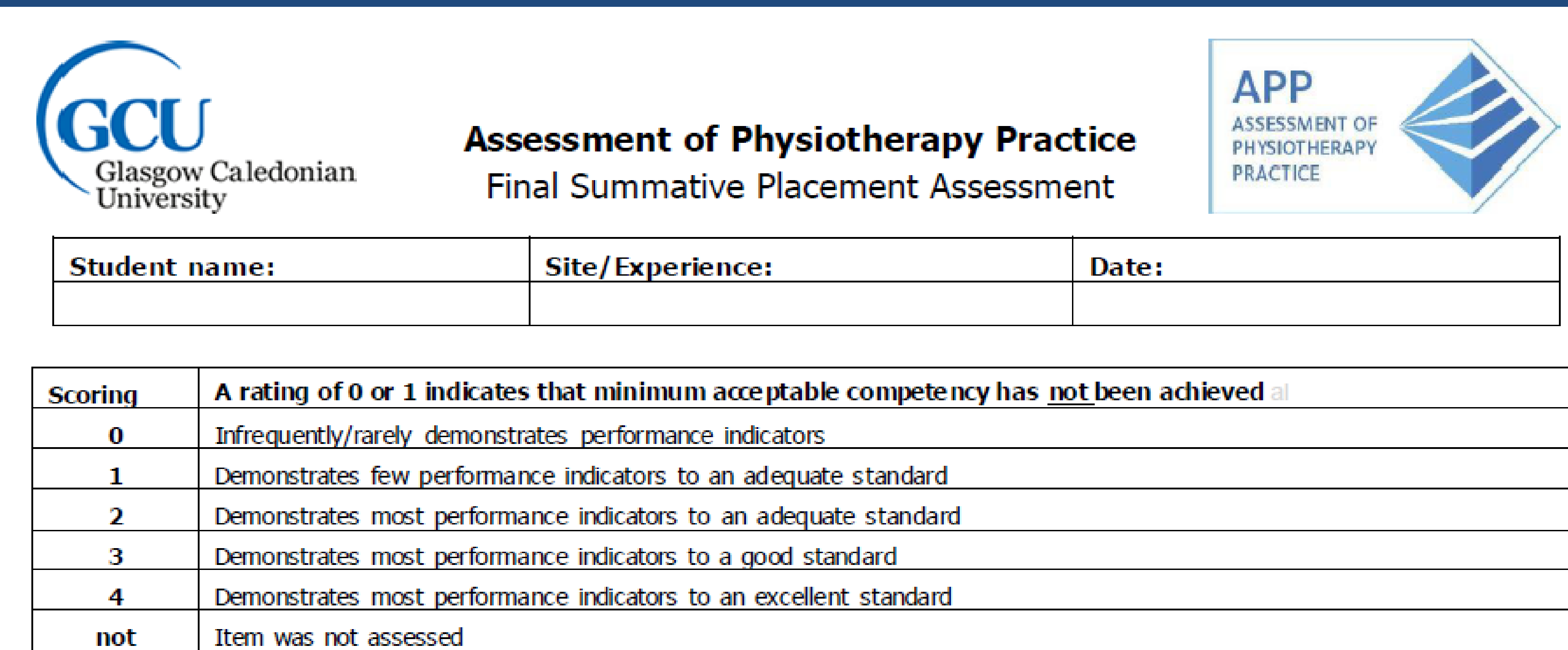

Professional Behaviour Circle one number only

Demonstrates an understanding of patient/client rights and consent $\quad \begin{array}{lllllllll}0 & 1 & 2 & 3 & 4 & \text { not assessed }\end{array}$

Demonstrates commitment to learning

Demonstrates ethical, legal \& culturally sensitive practice

. Demonstrates teamwork

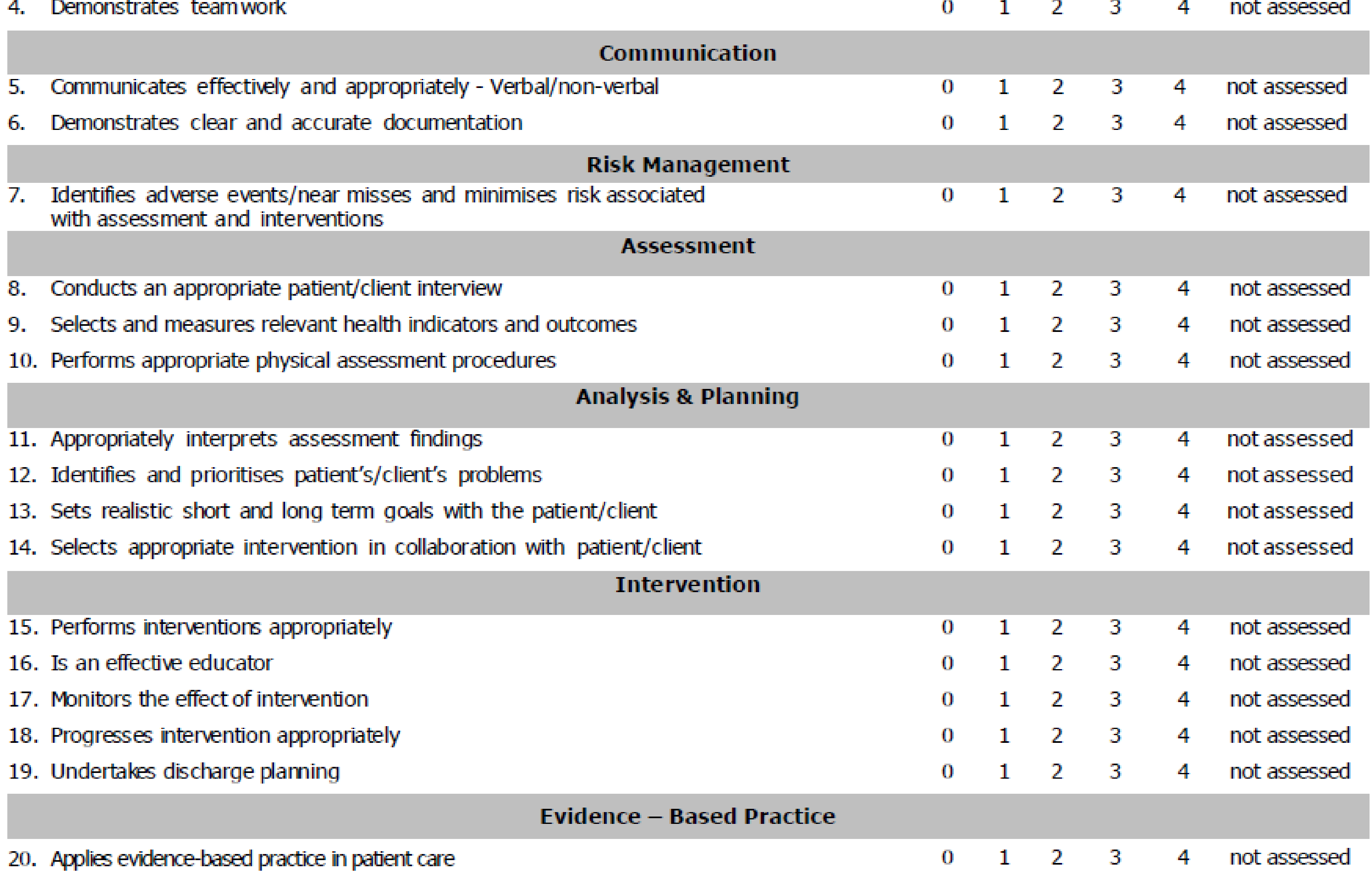

20. Applies evidence-based practice in patient care

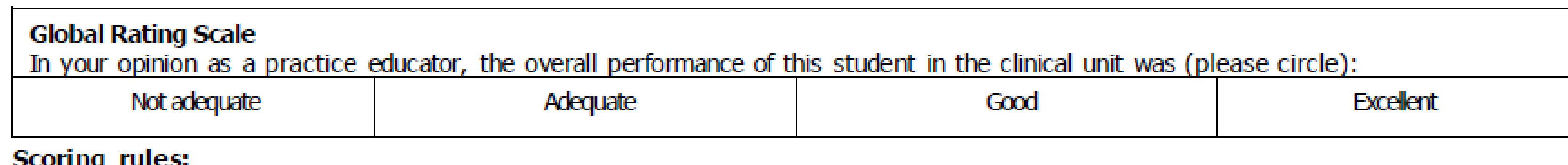

Scoring rules:
Circle not aseesed only if the student has not had an opportunity to demonstrate the behaviour

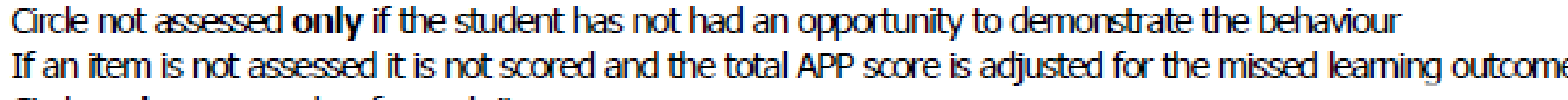

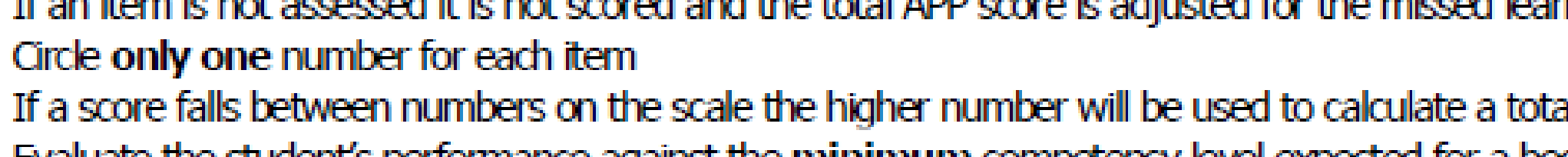

Purpose
- The aim of this project was to implement, pilot and evaluate the use of the Assessment of Physiotherapy Practice instrument across all pre-registration practice placements at Glasgow Caledonian University (GCU).

- In particular, features such as transparency of marking, consistency and quality of feedback to students, feasibility and acceptability were evaluated.

\section{Outcome}

- Feedback from pilot sites was very positive.

- Educators expressed that the behaviour focussed performance criteria of the APP considerably increased the ease and clarity of scoring students' performance, which also assisted practitioners in providing specific feedback to students.

- Students, in the main, were content with the use of the instrument, also appreciating the clear performance criteria.

- Uncertainty was voiced by both educators and students about the APP instrument grading all students to 'beginning/ entry level' standards of practice.

Discussion \& Conclusions

- An 18-month process of consultation and piloting the APP instrument allowed it to be adopted into practice in all pre-registration Physiotherapy programmes at the University.

- Feedback indicated that both practice educators and students felt that the instrument was acceptable and its clear performance criteria increased its feasibility for practice.

- Ongoing refinement of training workshops is required, particularly in relation to educating practitioners as to their expectations of 'beginning/ entry level' standards of practice.

\section{Impact and Implications}

- The use of the APP instrument is recommended for Physiotherapy preregistration programmes seeking a validated practice placement assessment method.

- Defining learning outcomes through behaviourally oriented performance criteria improves clarity of scoring for educators and enhances student feedback.

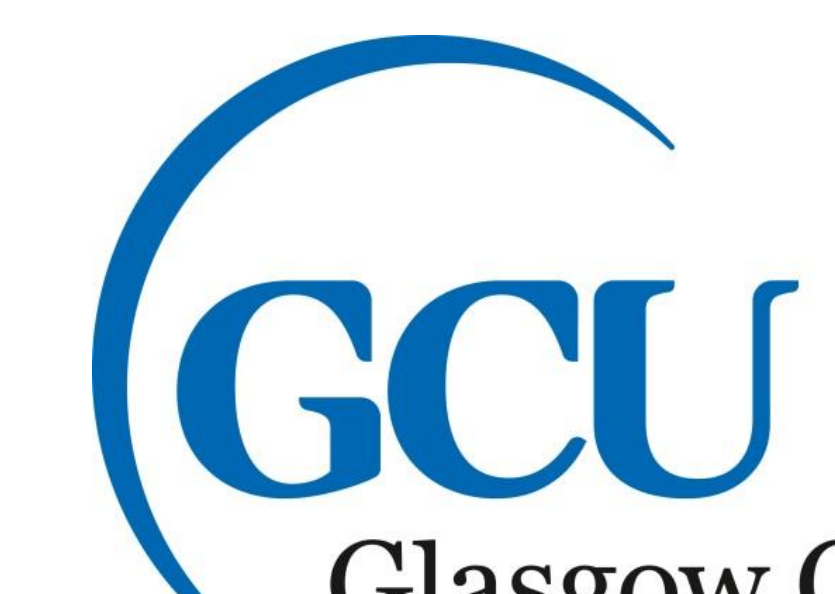

Glasgow Caledonian

University

Key References:

1. Dalton M, Davidson M and Keating I 2011. The assessment of physiotherapy practice. (APP) is a valid measure of professional competence of physiotherapy students: a cross-sectional study with Rasch analysis. Australian Journal of Physiotherapy, Vol 57, pgs 239-246.

2. Dalton M, Davidson M and Keating J 2012. The assessment of physiotherapy practice (APP) is a reliable measure of physiotherapy

competence in physiotherapy students: a reliability study. Australian Journal of Physiotherapy, Vol 58, pgs 49-56.

Funding Acknowledgement: This project was not funded.

Authors' Acknowledgement: Thanks go to not only the staff, students and practice educators involved in the introduction and pilot 